\title{
INTERTEXTUALIDADE E MEMÓRIA LITERÁRIA: A LEITURA COMO PRÁTICA DE MEMÓRIA EM RUI KNOPFLI
}

\author{
Otavio Henrique Meloni \\ (Instituto Federal do Rio de Janeiro - CVR)
}

\section{RESUMO}

Escrita e leitura são práticas indissociáveis, bastante íntimas e reveladoras de um profundo exercício de memória. Por mais pessoal que seja tal exercício, a memória sempre compartilha e associa fragmentos da esfera íntima com aspectos sociais e culturais. Por isso, quando pensamos na memória que é construída por intermédio das leituras de um indivíduo, temos várias esferas de pensamento e reflexão sobre uma mesma realidade, ainda que transformada por seu olhar de leitor. Este trabalho pretende discutir o papel das memórias literárias na construção do universo poético do moçambicano Rui Knopfli, levando em consideração sua condição de "desterritorializado" e a necessidade de afirmar um local de pertença (a leitura) como passível de referência. Tal local de segurança se fortalece na junção da memória literária com a intertextualidade que ela provoca. Acreditamos, assim, que as memórias literárias assumem o papel de local de pertença para o sujeito poético do moçambicano, amenizando suas fraturas de naturalidade, afirmando e justificando a existência deste sujeito por meio de sua experiência de leitura.

PALAVRAS-CHAVE: memórias literárias, Rui Knopfli, intertextualidade.

\section{ABSTRACT}

Reading and writing practices are inseparable, quite intimate and revealing a deep memory exercise. For most people it is such an exercise, and always shares the memory associated intimate fragments with social and cultural aspects. So when we think of memory that is built through the readings of an individual, we have various spheres of thought and reflection on the same reality, even transformed by his gaze reader. This paper discusses the role of literary memoirs in building the poetic universe of Mozambican Rui Knopfli, taking into account their condition "deterritorialized" and the 
need to assert a place of belonging (reading) as bound reference. This site security is strengthened at the junction memory literary with intertextuality that it causes. We thus believe that the literary memoirs assume the role of place belongs to the poetical subject of Mozambique, softening their fractures of naturalness, stating and justifying the existence of the subject through their reading experience.

KEYWORDS: literary memoirs, Rui Knopfli, Intertextuality.

"Que outros se vangloriem das páginas que escreveram; eu me orgulho das que li”. Jorge Luis Borges ${ }^{1}$

As palavras do argentino Jorge Luis Borges são as mais adequadas para iniciar nossas reflexões acerca da leitura e de um modo de leitura específico: uma leitura produtora. Não é preciso ser grande conhecedor da obra desse escritor argentino para saber que uma de suas principais obsessões criativas é o próprio ato da leitura como espécie de escrita ou reescrita de um texto. Talvez o momento mais emblemático destas afirmações na escrita borgiana seja o célebre conto "Pierre Menard, autor do Quixote"2, incluído em suas Ficções, publicação de 1944 (2007a). O fato é que Borges entendia a leitura como atividade propulsora do universo - para utilizar um termo muito querido ao argentino. Nesse sentido, já podemos questionar mais lucidamente os versos da epígrafe para compreender melhor o que fazem aqui. Valorar mais o que se leu do que o que escreveu ao longo da vida, isto vindo de um autor consagrado por crítica e público, nos faz pensar na relevância que o processo da leitura assume na compreensão de mundo e nas expectativas do autor quanto à literatura e à própria vida.

Além disso, tanto a escrita quanto a leitura são gestos profundamente individuais no que diz respeito ao ato laboral. É um homem que senta em sua poltrona e se põe a ler um livro que escolheu e é o mesmo sujeito que, não importa por qual motivo, se lança, mais tarde, em sua escrivaninha, à aventura de uma folha em branco, ao desafio da escrita. Não queremos, com tal ilustração, estabelecer uma ordem ou um processo de funcionamento e encadeamento das duas atividades, apenas desejamos ressaltar como as duas atividades são por demais pessoais. Com isso, entendemos que um autor, que expõe claramente aos seus leitores os dois procedimentos em sua obra, trabalha constantemente com duas esferas do íntimo, uma espécie de resguardo que ao mesmo tempo - e contraditoriamente - pretende mais se mostrar do que se esconder. Por isso entendemos que a utilização da leitura como propulsão da escrita é um ato de valoração da memória em todo o processo de criação do espaço ficcional, seja ele lírico ou narrativo. Então, se o espaço da escrita se transforma em um espaço 
de segurança, ainda que deslocado dos locais de pertença mais diretos, e a leitura pregressa desse sujeito sustenta, em muitos sentidos, tal espaço, logo a leitura passa a ser um elemento constituinte desse percurso memorialístico. Leitura e escrita, portanto, funcionarão, na formação do universo poético de Rui Knopfli, como elos entre o sujeito (que lê e escreve) e sua memória (de vida e de leitura).

Chegamos, então, ao ponto principal de discussão quando pensamos na leitura como chave na estrutura e criação de um universo literário: seus enlaces com a memória. Ainda que não haja um conceito estruturado por completo do que seria uma memória literária, encontramos alguns bons argumentos neste caminho se nos debruçarmos, por exemplo, em textos de Proust ou do próprio Borges. Mas, antes, é interessante que revisitemos Henri Bergson em sua investigação sobre os processos de formação da memória e a utilização consciente desses processos.

Ao abrir a sétima edição de Matéria e memória, de Henri Bergson, o leitor encontrará um prefácio, escrito pelo filósofo, que afirma logo nas primeiras linhas: "Este livro afirma a realidade do espírito, a realidade da matéria, e procura determinar a relação entre eles sobre um exemplo preciso, o da memória" (BERGSON, 1999, p. 1). Se entendermos, como Bergson, que a memória é um exemplo concreto que une a matéria ao espírito, ou seja, que de alguma forma aproxima um ser de sua completude através das relações que este ser é capaz de estabelecer com o tempo, os acontecimentos de sua vida e os mecanismos de registro e recuperação de tais acontecimentos, percebemos que tal capacidade humana é fundamental para a existência social. Lembrar e esquecer são atividades comuns aos seres humanos, mas o que cada um deles faz com sua memória, como recria suas lembranças ao longo dos anos, depende de uma atividade ficcional que, certamente, irá variar de acordo com suas intenções e necessidades. Como sabemos, ainda por Bergson, todo ato de recuperação da memória é um ato de recriação já que nós nunca registramos em sua totalidade cada acontecimento; para além disso, sabemos que os dispositivos que nos trazem uma memória espontânea ou emotiva são quase sempre sensoriais e extremamente subjetivos. Lembrar, portanto, é também criar. Ao recuperar em nossa memória um acontecimento ou episódio, nos fundamentamos em fragmentos que nos remetem ao ocorrido, mas, para transformar tais fragmentos em algo que possua sentido e/ou certa linearidade, preenchemos as lacunas com o que acreditamos ter ocorrido, ou, em casos mais extremos, com o que gostaríamos que tivesse acontecido.

Desse modo, os processos de formação da memória para Bergson podem ocorrer por duas maneiras distintas - o que, segundo o filósofo, estabelece dois tipos de memória. No primeiro, estariam posicionadas as atividades que repetimos diariamente e por isso memorizamos, uma espécie de memória do corpo que se constrói pela prática repetida de gestos e que recorda de tal prática pelo exercício da própria prática. No segundo caso, encontraríamos outra vertente da memória, mais associada às repre- 
sentações do que às ações. Nesse caso - que é o que mais nos interessa -, a memória é formada por episódios que são armazenados pela ordem de importância que lhes atribuímos e sua recuperação parte necessariamente da representação de um desses episódios. Será, portanto, sobre essa representação que os reconstruiremos de modo que eles façam sentido em nosso presente. Oportunamente, para nós, um dos exemplos citados por Bergson é o da leitura:

A lembrança de determinada leitura é uma representação, e não mais que uma representação; diz respeito a uma intuição do espírito que posso, a meu bel-prazer, alongar ou abreviar; eu lhe atribuo uma duração arbitrária: nada me impede de abarcá-la de uma só vez, como num quadro. Ao contrário, a lembrança da lição aprendida, mesmo quando me limito a repetir esta lição interiormente, exige um tempo bem determinado, o mesmo que é necessário para desenvolver um a um, ainda que em imaginação, todos os movimentos de articulação requeridos: portanto não se trata mais de uma representação, trata-se de uma ação. (BERGSON, 1999, p. 87)

Como podemos notar, Bergson opõe as lembranças por representação às lembranças por ação dentro do próprio ato da leitura. É verdade que a leitura pode ser mecanizada, como no ato educacional de memorizar uma lição, por exemplo, ler exaustivamente uma mesma passagem para torná-la inerente ao nosso saber, ainda que pelo prazo necessário para sua utilização. Por outro lado, em seu sentido mais amplo, a leitura constitui uma representação e é, por isso, um gesto mais próximo do aprender de cor: uma memória que registramos através de um intuitivo prazer gerado pelo que lemos ou por elementos que envolvem o ato da leitura, como o local, a época, o momento, algum acontecimento inesperado, etc.

Nesse caso, o pensamento do filósofo é bastante proveitoso para nossa análise, já que cremos, em um primeiro momento, que os autores-leitores trazem para seu universo de escrita aquelas leituras que, de certa forma, aprenderam de cor. Queremos dizer com isso que a memória literária dos autores se estabelece pelo mecanismo da representação, por lembranças fragmentadas de leituras que, por uma série de motivos, se reconstituem na escrita como matéria de criação e sustentação para uma realidade específica, o que, no caso de Knopfli, cremos ser a da naturalidade. Por isso, entendemos a escrita knopfliana como um espaço de exílio do sujeito diante das anomalias de sua relação com o conceito de pátria e de nacionalidade. A memória, portanto, e principalmente a literária, passa a funcionar como um importante mecanismo da escrita do autor, de uma vez que consegue, ao mesmo tempo, conciliar uma recuperação de fatos e episódios pessoais com suas leituras criadoras, no sentido barthesiano. Tomemos como exemplo o poema "Hereditariedade", do volume Mangas verdes com sal: 
Por trazer os olhos, a risca do cabelo e a gravata, onde os demais os usam habitualmente.

Não se descortina logo em mim o anjo caído,

$\mathrm{O}$ anjo só traído por certa fixidez

quase imperceptível do olhar, o anjo

que, em mim, perigosamente se dissimula.

Esse que faz de mim um descendente

em linha sinuosa de François Villon

poeta maldito, ladrão e assassino,

nosso santo padroeiro; do Bocage

de olhar parado e face lombrosiana,

do divino marquês, de todas as taras suserano,

do Shakespeare, pederasta e agiota,

de Charles Baudelaire, corruptor e perverso

e pulha, do Verlaine etilizado,

do Pessoa idem e do Laranjeira

suicidado. Parente, primo e colateral

do Genet ratoneiro, desleal, corrécio

e paneleiro, de Fernlinghetti,

de Ginsberg e de Burroughs,

flores aberrantes de um braçado de maricas,

canteiro onde só por acaso não floresci.

Como só um fortuito jogo de circunstâncias

evitou que afogasse esta mágoa estrangulada

em brandies ou no sono dos alcalóides.

O meu lenitivo procura-o no lazer,

no tépido e moreno recolhimento que se acha

entre as pernas de uma rapariga,

lá onde o tempo pára e recomeça,

onde a metafísica realmente se anula,

lugar por excelência desse olvido,

de que o corpo magro de um efebo,

o álcool, a coca e certas taras,

são outras tantas razões plausíveis

de sermos o tal anjo caído e maldito

que em mim se dissimula no trazer,

onde o trazem os demais, os olhos,

a risca do cabelo e a gravata.

(KNOPFLI, 2003, p. 248-249)

Como é perceptível aos olhos do leitor, as citações a nomes de escritores e suas características mais agudas são recorrentes na escrita desse poema. Knopfli busca mapear, nele, os caminhos que levam seu sujeito poético a se reconhecer como alguém "tocado" por um anjo caído. Tal imagem faz com que, imediatamente, nos remetamos aos versos de Drummond em 
seu "Poema de sete faces": "Quando nasci, um anjo torto/ desses que vivem na sombra/ disse: Vai, Carlos! ser gauche na vida" (ANDRADE, 2003, p. 5). A implícita referência se reforça quando aproximamos os dois poemas e compreendemos que, em ambos os casos, os sujeitos poéticos maldizem sua sorte e, a partir daí, constroem seus universos poéticos. Se Drummond nos avisa em seu poema que a solução não é uma rima, Knopfli se empenhará em mostrar que suas soluções (ou propostas de solução) são fruto de um entendimento de mundo construído por meio de suas leituras, que passam a ter o duplo poder de deflagrar as características mais íntimas de seu caráter e de acalmá-las como lenitivos da realidade. O trabalho desenvolvido pelo poeta moçambicano acaba por evidenciar traços marcantes das personalidades dos autores enumerados no poema, características que porventura - embora não necessariamente - permeiam suas obras. Assim, cremos que a intenção de Knopfli é demarcar a hereditariedade de seu sujeito poético através de um perfil de suas leituras, como se houvesse um gene literário formador de sua personalidade.

Tal proposta nos faz pensar no papel das leituras pessoais para a formação do sujeito poético de Knopfli e, por consequência, do próprio sujeito Knopfli, aquele que escreve. No poema "Hereditariedade", ao delinear um perfil genético de suas referências literárias, Knopfli menciona franceses, portugueses, ingleses e norte-americanos. Tal passeio indica que o que interessa nessa enumeração de autores, antes de uma definição estética da escrita/leitura, é sim buscar na literatura universal nomes que tenham sido importantes para sua formação de leitor e escritor, tanto por suas respectivas obras, quanto por particularidades referentes às suas biografias. Por isso, o sujeito poético se apresenta ao leitor por intermédio das características dos autores citados, o que nos faz descobrir que sua boemia é de Villon; a veia perversa, de Baudelaire; a pederastia e a ganância, de Shakespeare; o lado beberrão vem de Pessoa e Verlaine e a deslealdade, dos beatniks. Logo, as vertentes não muito convencionais dos referidos autores passam a explicar a figura controversa do sujeito poético de Knopfli, além de reforçar a referência anterior, geralmente de natalidade, como literária.

O trabalho intertextual - que é um trabalho de memória - de Knopfli, analisado por uma vertente mais genética do que epistemológica do texto, faz com que entendamos sua experiência de escrita como estratégia de afirmação subjetiva de suas ideias, evidenciando que seu posicionamento e suas reflexões diante de algumas situações específicas e, às vezes delicadas, têm, no pensamento e na escrita de outros autores, uma espécie de "fundamentação". Lembramos aqui das palavras do crítico e teórico Laurent Jenny:

O que caracteriza a intertextualidade é introduzir um novo modo de leitura que faz estalar a linearidade do texto. Cada referência intertextual é o lugar duma alternativa: ou prosseguir a leitura, vendo apenas no texto um fragmento como qualquer outro, que faz parte integrante da sintagmática do texto - ou então 
voltar ao texto-origem, procedendo a uma espécie de anamnese intelectual em que a referência intertextual aparece como um elemento paradigmático "deslocado" e originário de uma sintagmática esquecida. $\mathrm{Na}$ realidade, a alternativa apenas se apresenta aos olhos do analista. É em simultâneo que estes dois processos operam na leitura - e na palavra - intertextual, semeando o texto de bifurcações que lhe abrem, aos poucos, o espaço semântico. (JENNY, 1979, p. 21)

Cremos que Knopfli busca em sua escrita a simultaneidade proposta por Jenny para o processo intertextual. Dessa forma, a recuperação de um texto ou de uma personalidade anterior para o seu poema permite que migremos para outro nível de leitura, já que, ao reconhecer determinadas citações no texto que estamos lendo, passamos a considerar a possibilidade de que muitas outras ali existam, mesmo que não as reconheçamos imediatamente. Isso ocorre porque, se os leitores, de um modo geral, executam naturalmente a simultaneidade proposta por Jenny, o escritor assume seu papel de leitor e o transforma, semanticamente, em seu respectivo universo de criação. Nessa roda, leitor e autor se encontram cada vez que tocam o chão, sobem para vencer um novo espaço e se reencontram já recondicionados, tendo a certeza de que um afetou o outro entre os giros da reescrita.

Se em "Hereditariedade" Knopfli busca, em suas referências, marcas pessoais que reforcem uma aproximação quase genética com os precursores, há outros meios pelos quais o poeta moçambicano realiza o processo intertextual ao longo de sua obra. A recorrência do processo que integra leitura e escrita revela ao menos três registros no universo poético knopfliano. O primeiro deles recupera textos anteriores por seus títulos, como se processassem uma espécie de reescrita completa do original; o segundo registro trata das referências realizadas por meio de citações de autores; por fim, há uma terceira possibilidade, que trabalha com as citações de obras ou trechos de obra. Não obstante, o processo maior de construção do verso, muitas vezes, mescla as três possibilidades em um mesmo poema, o que acreditamos se tratar de um movimento natural em uma poética que prima por dar fluidez às citações que recupera. Cabe ressaltar que, nos três casos, a intertextualidade evidencia a importância da leitura na produção poética do moçambicano, deixando claro que há um autor-leitor por de trás da escrita, alguém que entende suas leituras como componentes necessários e condicionantes da realidade que o circunda. Nesse sentido, ler tais referências implica dois níveis de compreensão da obra de Knopfli: o primeiro, ligado diretamente à escrita e sua constituição; o segundo, vinculado às leituras particulares que o poeta revela ao seu leitor e que se tornam sintomas do processo de subjetivação da escrita.

Entendemos, portanto, que a leitura representa um escape consciente da realidade anômala que aflige o poeta, principalmente no que tange aos questionamentos acerca de sua naturalidade, atuando no sentido de ampliar as possibilidades do sujeito em sua sobrevivência diária. Em 
Knopfli, cremos que isso funciona de maneira quase natural, a partir do momento em que suas leituras e, por conseguinte, suas memórias literárias são mais capazes de o dizer do que sua condição de pertencente a algum lugar ou proveniente de alguma cultura em específico. O sujeito múltiplo que apontamos na escrita knopfliana e que acreditamos ser um duplo, não idêntico, do poeta em si, consolida-se em suas memórias literárias e metaforiza-se na própria condição universal - no sentido mais amplo do vocábulo - da literatura. O escritor francês Marcel Proust, em prefácio escrito para uma obra de John Ruskin, nos alerta que há, em alguns literatos, uma espécie de "doença literária" que os levaria a adorar os livros e a leitura de tal maneira que seriam capazes de viver intensamente em uma "sociedade dos livros":

Para ele [o literato], o livro não é o anjo que esvoaça assim que se abrem as portas do jardim celeste, mas um ídolo imóvel que ele adora pelo que é, que, em vez de receber uma dignidade verdadeira dos pensamentos que desperta, comunica uma dignidade factícia a tudo que o cerca. (PROUST, 2011, p. 43)

Não acreditamos que seja por completo o caso de Knopfli, mas é possível encontrar alguns dos principais sintomas da "doença literária" de que fala Proust na obra do poeta moçambicano, principalmente se nos ativermos ao fato de que, para o francês, um dos indícios mais fortes de tal doença seria a relação estreita do sujeito leitor com aquilo que lê, tanto como representação do espírito quanto no campo da materialização de tais representações no real que o cerca. É, porém, o próprio Proust que, no mesmo texto, absolve a prática que no início condenara, por perceber que os "defeitos" - para manter o termo utilizado pelo escritor - provenientes de tal "doença" revelam as imperfeições do espírito humano, que podem buscar "curas" em vários níveis, de acordo com o contexto social e intelectual de cada indivíduo:

Há, contudo, certos casos, certos casos patológicos, por assim dizer, de depressão espiritual para os quais a leitura pode tornar-se uma espécie de disciplina curativa e se encarregar, por incitações repetidas, de reintroduzir perpetuamente um espírito preguiçoso na vida do espírito. Os livros desempenham então um papel análogo ao dos psico-terapeutas para certos neurastênicos. (PROUST, 2011, p. 36)

Os livros - portanto, a leitura - desempenham um papel fundamental na constituição do sujeito poético de Rui Knopfli por serem também fundamentais para a condição humana do cidadão Rui Knopfli. As metáforas de doença e cura utilizadas pelo autor de Em busca do tempo perdido demonstram que o ato da leitura, na verdade, transcende as frivolidades de uma atividade de lazer, sendo responsável por conceder ao espírito humano o componente de ficcionalização necessária para que suportemos o real. Para alguns leitores, tal percepção se faz de maneira menos densa, 
por significar algo inconsciente, às vezes intuitivo; porém a potencialização da leitura como ficcionalização do real, quase sempre processada por escritores e pensadores, transforma o ato de ler em um processo de mão dupla, no qual o sujeito retém aprendizados e os recria na escrita. É o que Compagnon aponta em seu célebre livro O trabalho da citação:

A citação tenta reproduzir na escrita uma paixão da leitura, reencontrar a fulguração instantânea da solicitação, pois é a leitura, solicitadora e excitante, que produz a citação. A citação repete, faz com que a leitura ressoe na escrita: é que, na verdade, leitura e escrita são a mesma coisa, a prática do texto que é prática do papel. (COMPAGNON, 1996, p. 23)

Assim, evidencia-se a "leitura solicitadora e excitante" capaz de transformar a citação em elemento criador e provocador de memórias, porém sempre revelador de uma verdade incômoda para a maioria dos autores, verdade já apresentada pelo argentino Borges, quando afirma que "a história universal, talvez, a história da diferente entonação de algumas metáforas" (BORGES, 2007b, p. 17). Embora não acreditemos ser esse um problema para Rui Knopfli, compreendemos que esse é um dos principais motes de sua escrita: a perseguição a seus predecessores e suas respectivas obras. Tal mote promove o encontro constante do Knopfli leitor com o Knopfli escritor e evidencia as tensões existentes em um processo de escrita que compreende a citação e a referência como parte integrante de sua criação. Daí que sua escrita seja definida, no poema "O poeta é um fingidor" - citação explícita, aliás, à "Autopsicografia” de Pessoa -, como um mecanismo que causa tristeza enquanto entretece e entretece, assim, as próprias tristezas. Uma melancolia criativa dos grandes escritores, como bem assinala Kano:

É que escrever, bem feitas as contas, é sempre o drama da relação do escritor com seus mortos escolhidos, aqueles com que se revive página a página, entre leitura e escrita, a intuição contraditória de que é improvável criar antes de os ter lido, mas tanto mais impossível criar depois de os ter lido.

É a melancolia de todo escritor: não ter sido o primeiro a escrever as coisas que, no entanto, se não tivesse lido, talvez não estivesse apto a escrever. (KANO, 2011, p. 18)

É esse dilema de todo escritor que ronda a obra de Knopfli ao construir um universo poético estruturado sobre memórias literárias tão diversas e que introduzem, em sua escrita, suas leituras de outras escritas. Nesse caminho, criar depois de ter lido é mais recriar as leituras do que criar a escrita. Parte da obra de Knopfli se estrutura por sua obsessão com grandes autores. Perseguir seus predecessores, seus eleitos, é perseguir a escrita literária nas dores que ele não tem para recriar as que só ele tem. Tal concepção de leitura e memória das leituras como instrumentos de criação 
literária permearão toda a obra de Knopfli. No recorte que aqui propomos, vamos privilegiar alguns nomes com o intuito de detalhar o máximo possível como funciona esse processo de criação na obra do autor.

É o caso, por exemplo, dos poetas modernistas brasileiros Carlos Drummond de Andrade e Manuel Bandeira. Ambos se apresentam em recortes marcantes de suas respectivas obras, em duas oportunidades suscitadas pelo sujeito poético de Rui Knopfli como possíveis elementos de afirmação de uma identidade emocional que, se não soluciona as fraturas sociais e políticas, ao menos estabiliza em alguns pontos o processo de autorreconhecimento que se constrói ao longo da escrita. Cremos ser esse o caminho escolhido por Rui Knopfli para contrabalancear as lacunas identitárias em seu universo poético, já que são os elementos afetivos, como a própria literatura citada, que consolam o sujeito poético em seu labor. Algo que ocorre, por exemplo, com a pedra drummondiana no poema "A pedra no caminho":

Toma essa pedra em tua mão, toma esse poliedro imperfeito, duro e poeirento. Aperta em tua mão esse objecto frio, redondo aqui, acolá acerado.

Segura com força esse granito bruto. Uma pedra, uma arma em tua mão. Uma coisa inócua, todavia poderosa, tensa, em sua coesão molecular, em suas linhas irregulares.

Ao meio-dia em ponto, na avenida ensolarada, tu és um homem um pouco diferente. Ao meio-dia na avenida tu és um homem segurando uma pedra. Segurando-a com amor e raiva.

(KNOPFLI, 2003, p. 155)

No poema de Drummond, a pedra pode ser compreendida como muitas leituras já sugeriram e convencionaram - como os obstáculos encontrados pelo homem no trajeto de sua vida. Ela está isolada do sujeito, ainda que seja preponderante para gerar seu discurso e capaz de transformar sua percepção de mundo pelo simples fato de estar à sua frente, no meio do caminho. Há uma observação subjetiva que, por intermédio de uma recordação, permite que sujeito poético e leitor possam, ao mesmo tempo, perceber que a pedra sempre estará no meio do caminho, seja materialmente impedindo seu avanço, seja na memória de um fato que ainda é capaz de fatigar as retinas. Portanto, no poema do brasileiro, a pedra pode transcender sua materialidade para se transformar em um impedimento 
subjetivo. É partindo desse ponto que entendemos a proposta de Knopfli para o referencial da pedra, já que, para o poeta moçambicano, o impedimento continua sendo subjetivo, porém questionável e, principalmente, controlável. Quando Drummond associa a imagem da pedra à imagem do caminho, temos uma combinação que gera um sujeito poético observador, logo passivo diante dos acontecimentos. É essa passividade que Knopfli transforma em sua leitura, produzindo um sujeito poético que é aconselhado a tomar a pedra nas mãos para, a partir disso, potencializar sua subjetividade em ações de acordo com os "obstáculos" do caminho. Nesse sentido, as duas primeiras estrofes são dedicadas a descrições da pedra como um objeto capaz de assumir diferentes papéis conforme os anseios de quem a detém em suas mãos. As características científicas se mesclam com questões circunstanciais para culminar na visão de um homem renovado, que será apresentado, na última estrofe, propositalmente ao meio-dia, em uma avenida central. Esse é o ponto escolhido por Knopfli para fazer com que seu sujeito poético se reencontre com o criado por Drummond, já que os dois terminam seus respectivos poemas como "homens diferentes", transformados pela pedra e por suas potencialidades. Portanto, o caminho traçado por Knopfli em sua releitura do poema de Drummond conserva o poder transformador da figura da pedra, ainda que sua representação seja diferente.

A espécie de (des)equilíbrio que a pedra passa a exercer sobre a voz poética ao concentrar em suas mãos a potencialidade do objeto tem como intuito demonstrar ao próprio sujeito poético que, apesar de todas as influências externas, há algo que só pertence a ele, que não lhe pode ser tirado ou negado e que deve ser valorizado em seu processo de escrita. Tal proposta nos parece ser semelhante à do poema intitulado "Terra de Manuel Bandeira”, no qual Knopfli busca a idílica Pasárgada do modernista brasileiro para mensurar quão importante para ele são as coisas mais simples da vida, as pessoas que o cercam intimamente, ainda que, aos olhos de outrem, tivesse todos os motivos para disparar em fuga:

Também eu quisera ir-me embora pra Pasárgada,

também eu quisera libertar-me e viver essa vida gostosa que se vive lá em Pasárgada (E como seria bom, Manuel Bandeira, fugir duma vez pra Pasárgada!).

Entanto tudo me prende aqui a este lugar desta cidade provinciana.

Como deixar ao abandono o olhar Luminoso dessa mulher que eu amo? Quem responderá às inquietas Perguntas de minha filha pequena (cabelo curto, olhos de sonho)? 
Quem, no sereno da noite, para as beijar

com ternura e nos braços acalentar?

E esta vida, este sítio,

E estes homens e estes objectos?

$\mathrm{E}$ as coisas que amei e as que esqueci?

E os meus mortos e as doces recordações,

as conversas de café e os passeios no

entardecer fusco da cidade?

E o cinema todos os sábados, segurando

com força a mão de minha mulher?

Eles nem são amigos do rei

e a entrada lá é limitada.

Por isso é que eu não fujo

duma vez, pra Pasárgada.

(KNOPFLI, 2003, p. 44)

A subjetividade construída por Manuel Bandeira no poema original é recobrada aqui por Knopfli para subverter os motivos e destinos de quem avista a possibilidade de fugir para Pasárgada como uma necessidade. Se nos versos de Bandeira o sujeito poético parte da certeza, "vou-me embora pra Pasárgada", para afirmar seu desgosto com a vida que leva e instaurar um local imaginado em que tudo que deseja pode se realizar, acentuando uma desvalorização da experiência real da vida, em Knopfli a noção de realidade e o apego ao seu local afetam o sujeito que fala nos versos, contaminando seu desejo de fuga e assim transformando-o em uma mera possibilidade descartada. É por isso que o encontramos logo na primeira estrofe lamentando com o poeta brasileiro, já em tom de quem não pode ir embora, o que evidencia que o "não poder" está inversamente atrelado ao "querer ir". Nesse sentido, o balanço feito pelo poeta moçambicano enumera fatos, lugares e pessoas que pesam em sua decisão de abdicar da idílica Pasárgada, principalmente porque ela - nos olhos originais de Bandeira - acolhe homens em seus signos de solidão. Esse motivo faz com que o moçambicano se dê conta, por exemplo, de que sua esposa e sua filha não são "amigas do rei", logo não poderiam ir junto, ou ainda que fossem, não teriam os mesmos privilégios. Knopfli aponta para a interiorização do problema como solução mais lógica do que a fuga: ficar é afirmar-se pertencente não a um país delimitado por fronteiras políticas, mas integrante de uma experiência de vida que transcende tais formalidades e o impede de abdicar de seus enlaces afetivos, com a terra, com a família e com o amor.

Novamente, como no caso da pedra drummondiana, é o sujeito que tem nas mãos a capacidade de refletir e decidir sobre o que fazer com tais signos poéticos. A pedra, potência que deixa de ser obstáculo para se tornar arma, nisso só se converte, pois salta do chão (caminho) para as mãos do sujeito - são seu amor e sua raiva, dosadas de acordo com a situa- 
ção, que decidem a função mais adequada. É nesse contexto que Pasárgada, o idílico refúgio que tantos outros poetas, de tantas nacionalidades, já recuperaram como imagem do lugar perfeito, se apresenta ao sujeito poético, que, no entanto, declina do implícito convite: por mais tentadora que seja a proposta, cabe a ele decidir se quer ou não aceitá-la. Dessa forma, Knopfli demonstra que nos dois casos há uma decisão pessoal que se sobrepõe ao convencional e, para tanto, trabalha com elementos do cotidiano com a finalidade de demarcar que as fronteiras do sujeito são e sempre serão suas convicções e seus enlaces emocionais.

Se os dois poetas brasileiros são recuperados com o intuito de refletir sobre uma identidade que se alicerça e, posteriormente, se afirma, sobretudo, em âmbito subjetivo, é nas literaturas de língua inglesa que o caminho de leitura traçado por Knopfli irá confluir para acentuar as linhas dramáticas de seu discurso poético. Portanto, o sujeito, fragmentado perante a conjuntura política e social de Moçambique no período do pré-independência e posteriormente no exílio voluntário do pós-75 - que se consolida por sua experiência de vida e de África e que incorpora nesse magma elementos particulares de seu cotidiano como traços de identificação -, encontrará, na experiência de suas leituras em língua inglesa, principalmente nas peças de Shakespeare, a carga dramática que seus versos suscitam. Embora sejam muitos os nomes representativos desses universos literários que aparecem ao longo de toda a obra do moçambicano, por uma questão de recorte, tentaremos centrar nossas análises especificamente no diálogo com William Shakespeare, na medida em que o entendemos como o principal "interlocutor" da poesia de Knopfli.

O poeta e dramaturgo inglês dos séculos XVI e XVII, autor de grandes obras do que hoje entendemos por literatura, povoará de ponta a ponta o universo poético de Rui Knopfli. Shakespeare estará presente na escrita de Knopfli como impulso criador - com seus personagens e seu estilo na construção de figuras poéticas, tal qual no poema "Três falas inventadas para três personagens de Shakespeare" -, e, ainda, como personagem/homenageado, como em "Glosa de Shakespeare". A escrita poética de Knopfli absorverá, em muitos casos, a aflição subjetiva dos personagens principais de grandes dramas como Hamlet e Macbeth, por exemplo. Entendemos que tal "apropriação" da carga dramática criada pelo dramaturgo inglês se reflete na constituição do sujeito poético knopfliano, evidenciando os dramas pessoais, as cisões sociais e políticas e a afirmação identitária, já atravessadas pela escrita pessoana e pelas releituras de Drummond e Bandeira em outra escala. As memórias literárias, portanto, funcionariam para além da questão estética, mas como um subterfúgio de estabilização de um sujeito cindido e por isso confuso diante de seus grandes dilemas de identidade e representação em seu tempo. Esse sujeito que ainda carece de autocompreensão é o mesmo que solicita discrição, transmutando-se no dramaturgo inglês ao escrever sua glosa: 
Não chores por mim, quando tiver morrido, mais do que o tempo de meu corpo baixar à terra.

E se, ao leres depois meus versos, te comover a memória furtiva da mão que o compôs,

reprime vivamente as lágrimas que aos olhos te assomarem. Lê, sim, meus versos arredando-os bem da carne corrompida e da fria insensibilidade habitadas outrora.

De duas vidas que tive, uma logo soube finita. Pela outra, quanto podia, fiz para que o não fosse, ciente que daquela me apartando, deste tudo ignoraria.

Se ao leres-me pois, atenta, a mágoa sentida, de lembranças minhas isenta, nasça toda só de um verso comovido, terei então vivido.

(KNOPFLI, 2003, p. 332)

A glosa, na verdade um soneto nos moldes shakespearianos, apresenta um sujeito poético preocupado com seu legado, principalmente com seu legado literário, os versos que se imortalizam nas leituras de outrem. Assim, direcionando a voz a um interlocutor que nos parece o leitor como categoria, de modo bastante amplo, Knopfli, por seu sujeito poético, apresenta o desejo de que sua obra seja lida pelo que a constitui e não por sua vida pessoal, por isso levar a vida, logo no inicio do poema, ao seu cabo: a morte. Nesse sentido, o sujeito poético não se resume a pedir que se evitem tristezas extremas por seu passamento, mas, sobretudo, expressa o desejo de que seus versos se mantenham vivos pelo que são e não pelo que ele foi. Por isso, o primeiro terceto aponta para duas vidas, sendo, uma delas, a física, entendida desde cedo como finita, e a outra, literária - e é por esta que ele decidiu lutar para que se mantivesse intacta, de tal maneira que as duas se afastaram ao longo do tempo. Essa angústia de conviver, metaforicamente, em duas vidas - que estão sob seu controle, mas que o fazem refletir a ponto de pedir ao leitor que não as confunda - é sublimada no verso final, quando, ao concluir o raciocínio, deixa claro que ele só terá vivido se a emoção que contaminar o leitor seja a de um verso isoladamente e não a de sua lembrança física imbricada ao texto.

O sujeito poético, portanto, se divide em máscaras para criar uma glosa de Shakespeare e, ainda assim, ser subjetivo a ponto de refletir mais sobre sua condição do que sobre a de seu homenageado/referente. Nesse sentido, o soneto XII de Shakespeare poderia ser uma espécie de ponto de partida, não só para a "glosa" de Knopfli, mas para o confronto do sujeito poético com o tempo e suas dualidades ao longo de sua escrita. Logo, viver na boa leitura de um seu verso é vencer a luta inglória contra o tempo, manter-se vivo no que se quer fazer, ainda que pelo olhar de outro, o leitor. Nas palavras do poeta inglês: "Contra a foice do Tempo é vão combate/ Sal- 
vo a prole, que o enfrenta se te abate." ${ }^{\text {. O }}$ verso é a prole pretendida, aquela que ainda enfrentará o tempo após sua morte, após a epicurista dissolução de seus átomos.

A literatura em língua inglesa ainda permeará a obra de Knopfli por outros meios que não a reflexão a partir de leituras, como ocorre na reescrita do poema "If" de Rudyard Kipling, mas também por intermédio de citações diversas, além da utilização da própria língua inglesa, ora dividindo espaço com a portuguesa, ora dominando a conduta linguística do texto. Há ainda figuras emblemáticas, como T. S. Eliot, que desponta como uma das referências mais presentes de Knopfli no que diz respeito à estética do poema, além de citações e referências a manifestações culturais tipicamente norte-americanas, como o Jazz, por exemplo. O fato é que o influxo cultural que os jovens de Lourenço Marques, ainda enquanto colônia de Portugal, tinham com a África do Sul faz com que a poesia de Knopfli dialogue com outros espaços culturais que não o da metrópole, Lisboa. Assim, seu posicionamento político quanto aos movimentos de libertação e o recrudescimento do salazarismo, para além das questões sociais já discutidas, reflete um homem que tem a necessidade de entender seu lugar no conflito antes de assumir o conflito como seu. Esse momento de reflexão pessoal, que nos mostra um homem que pode dividir rancor e alegria no mesmo verso, como segurar a pedra com amor e ódio no meio da avenida, é o espaço intervalar de criação desse moçambicano que passa a se entender como fruto do desnível entre seus anseios internos e as "obrigações" externas que o pressionam.

Acreditamos, pois, que a literatura, a leitura e, por consequência, a memória - como representação mais íntima do conhecimento de mundo de um sujeito - surgem para Rui Knopfli como um espaço de afirmação identitária que, se não soluciona (e não tem mesmo esse poder), ameniza as divergências geradas pela sua experiência africana. Quando o olhar do outro passa a ser um definidor mais importante para quem se é do que propriamente o que se entende por assim ser, resta ao sujeito buscar um isolamento seguro, no qual seus semelhantes e convivas podem ser manipulados de acordo com suas demandas subjetivas. Cidades são refeitas, amigos são recuperados e os desejos, estendidos sobre a calçada dos versos, como que para tomar sol. Se o futuro é incerto, sempre incerto, cabe a ele assumir a condição do velho colono, olhar para o passado questionando o presente:

Sentado no banco cinzento entre as alamedas sombreadas do parque. Ali sentado só, àquela hora da tardinha, ele e o tempo. O passado certamente, que o futuro causa arrepios de inquietação. Pois se tem o ar de ser já tão curto, o futuro. Sós, ele e o passado, os dois ali sentados no banco de cimento.

(KNOPFLI, 2003, p. 151) 


\section{REFERÊNCIAS BIBLIOGRÁFICAS}

ANDRADE, Carlos Drummond de. Poesia completa. Rio de Janeiro: Nova Aguilar, 2003.

BERGSON, Henri. Matéria e memória. Trad. de Paulo Neves. São Paulo: Martins Fontes, 1999.

BORGES, Jorge Luis. Ficções. Trad. de Davi Arrigucci Júnior. São Paulo, Companhia das Letras, 2007a.

Outras inquisições. Trad. de Jorge Schwartz e Maria Carolina de Araújo. São Paulo: Companhia das Letras, 2007b.

COMPAGNON, Antoine. O trabalho da citação. Trad. de Cleonice Mourão. Belo Horizonte: Editora da UFMG, 1996.

JENNY, Laurent. A estratégia da forma. Trad. de Clara Crabbé Rocha. Poétique, n. 27, Coimbra, pp. 5-49, 1979.

KANO, Ivan Takashi. Da leitura à escrita, as memórias camilianas de Pedro Paixão e Mário Cláudio. 2011, 135f. Dissertação (Mestrado em Literatura Portuguesa e Literaturas Africanas de Língua Portuguesa). Universidade Federal Fluminense, Niterói, 2011. Disponível em http://www. bdtd.ndc.uff.br/tde_busca/arquivo.php? codArquivo=4849, consultado em 23/04/2013.

KNOPFLI, Rui. Obra poética. Lisboa: Imprensa Nacional Casa da Moeda, 2003.

PROUST, Marcel. Sobre a leitura. Trad. de Carlos Vogt. Campinas: Pontes, 2011.

Recebido para publicação em 21/05/2013

Aprovado em 22/07/2013

\section{NOTAS}

1 Estes são os versos iniciais do poema “Um leitor” em O elogio da sombra, de 1969.

2 No conto, Pierre Menard é um escritor que pretende escrever o Quixote de Cervantes com as mesmas palavras, a mesma ordenação e pontuação. Na escrita do conto, fica clara a ideia de Borges de que a leitura é peça fundamental para a escrita de um texto e que devem ser levados em conta também a contextualização da leitura em seu tempo e realidade e, ainda, as intenções de quem lê. Por isso, entendemos que o Quixote de Menard jamais poderia ser o mesmo de Cervantes, ainda que textualmente o fosse.

3 Poema disponível em http://www.algumapoesia.com.br/poesia2/poesianet169.htm. Data de acesso: 30/05/2013. 